\title{
Why patients with inflammatory bowel disease use or do not use complementary and alternative medicine: A Canadian national survey
}

\author{
Feng X Li PhD ${ }^{1}$, Marja J Verhoef $\mathrm{PhD}^{1}$, Allan Best $\mathrm{PhD}^{2}$, Anthony Otley $\mathrm{MD}^{3}$, \\ Robert J Hilsden MD PhD FRCPC ${ }^{4}$
}

FX Li, MJ Verhoef, A Best, A Otley, RJ Hilsden. Why patients with inflammatory bowel disease use or do not use complementary and alternative medicine: A Canadian national survey. Can J Gastroenterol 2005;19(9):567-573.

BACKGROUND: The use of complementary and alternative medicine (CAM) is common in patients with inflammatory bowel disease (IBD).

OBJECTIVES: To determine the factors associated with use of CAM, the reasons commonly cited for use or nonuse of CAM, and the correlations between the factors associated with use of CAM and reasons for CAM use.

SUBJECTS: The study included 2828 members of the Crohn's and Colitis Foundation of Canada.

METHODS: Subjects were mailed a questionnaire that included items on demographic characteristics, disease and treatment history, health attitudes and behaviours, and reasons for use or nonuse of CAM. Logistical regression was used to determine significant associations with current CAM use.

RESULTS: In patients with Crohn's disease and ulcerative colitis, CAM use was associated with more severe disease activity, use of CAM for other purposes, use of exercise and prayer for IBD, and a desire for an active role in treatment decisions. CAM use was also associated with younger age in those with Crohn's disease, and less confidence in their IBD physician in those with ulcerative colitis. The most common reasons for CAM use were a desire for greater control, having heard or read that CAM might help, and the emphasis CAM places on treating the whole person. The most common reasons for not using CAM were that conventional treatments were successful, that not enough was known about CAM and a belief that CAM would not help.

CONCLUSION: Disease activity and health attitudes and behaviours, but not demographic characteristics, are associated with CAM use by those with IBD.

Key Words: Complementary and alternative medicine; Health behaviours; Inflammatory bowel disease; Patient decision-making

\section{Pourquoi les personnes atteintes d'une maladie inflammatoire de l'intestin utilisent-elles ou n'utilisent-elles pas les approches complémen- taires et parallèles en santé : Une enquête pancanadienne}

HISTORIQUE : Le recours aux approches complémentaires et parallèles en santé (ACPS) est courant chez les personnes atteintes d'une maladie inflammatoire de l'intestin (MII).

OBJECTIFS : Déterminer les facteurs associés à l'usage des ACPS, les raisons couramment invoquées pour utiliser ou ne pas utiliser les ACPS et les corrélations entre les facteurs associés à l'usage des ACPS et aux raisons de les utiliser.

SUJETS : L'étude incluait 2828 membres de la Fondation canadienne des maladies inflammatoires de l'intestin.

MÉTHODOLOGIE : Les sujets ont reçu un questionnaire par la poste, incluant des questions sur les caractéristiques démographiques, l'historique de la maladie et du traitement, les attitudes et les comportements envers la santé et les raisons d'utiliser ou de ne pas utiliser des ACPS. La régression logistique a permis de déterminer des associations significatives avec l'usage courant d'ACPS.

RÉSULTATS : Chez les personnes atteintes de la maladie de Crohn ou de la colite ulcéreuse, le recours aux ACPS s'associait à une activité plus grave de la maladie, à l'utilisation des ACPS pour répondre à d'autres besoins, au recours à l'exercice et à la prière à l'égard de la MII et au désir de jouer un rôle actif dans les décisions relatives au traitement. L'usage des ACPS s'associait également à des personnes plus jeunes dans les cas de maladie de Crohn, et à une moins grande confiance envers le médecin soignant leur MII dans les cas de colite ulcéreuse. Les raisons les plus invoquées pour utiliser des ACPS étaient le désir d'avoir plus de contrôle, avoir entendu parler ou lu que les ACPS pouvaient être utiles et l'importance accordée au fait que les ACPS soignent l'individu dans son ensemble. Les principales raisons invoquées pour ne pas utiliser les ACPS étaient que les traitements classiques fonctionnaient, qu'on n'en savait pas assez sur les ACPS et que les ACPS ne seraient pas utiles.

CONCLUSION : L'activité de la maladie et les attitudes et les comportements envers la santé, mais non les caractéristiques démographiques, sont reliés au recours à l'usage des ACPS chez les personnes atteintes d'une MII.

the definition of CAM, they show a trend of increasing CAM use by this population. This is not surprising, because the boom in CAM use by the general population is well-documented (9). However, why people with IBD use or do not use CAM is incompletely understood. General population surveys $(10,11)$ have linked CAM use to several factors, including
The use of complementary and alternative medicine (CAM) by people with inflammatory bowel disease (IBD) is common. Previous studies have reported rates of CAM use ranging from $4 \%$ to $13 \%$ in the late 1980 s $(1,2)$ to $31 \%$ to $51 \%$ a decade later (3-8). Although these rates may not be directly comparable with each other due to the differences in

\footnotetext{
${ }^{1}$ Department of Community Health Sciences, University of Calgary and the Centre for Clinical Epidemiology and Evaluation, Calgary, Alberta;

${ }^{2}$ University of British Columbia, Vancouver, British Columbia; ${ }^{3}$ Department of Medicine, Dalhousie University, Halifax, Nova Scotia;

${ }^{4}$ Department of Medicine, University of Calgary and the Centre for Clinical Epidemiology and Evaluation, Calgary, Alberta

Correspondence: Dr Robert Hilsden, University of Calgary, 3330 Hospital Drive Northwest, Calgary, Alberta T2N 4N1.

Telephone 403-210-9355, fax 403-283-6151, e-mail rhilsden@ucalgary.ca
} 
higher education and income, poorer health status, a holistic orientation to health and an interest in spirituality. Previous studies of IBD patients have examined demographic and disease characteristics, but findings have not been consistent. However, these studies have been limited by relatively small sample sizes and the use of predominantly tertiary care gastrointestinal clinic samples. Therefore, the authors sought to examine CAM use in a large and diverse sample of people with IBD.

Studies examining why people do not use CAM are lacking. Understanding who uses or does not use CAM, and why, is important for several reasons. First, it would help to better understand the phenomenal growth of CAM. Second, it could indicate aspects of conventional medical care that patients find unsatisfactory, leading to improved patient care. Third, it would help clinicians to better understand their patients and to better counsel them about coping with their disease, including the use of CAM, thereby allowing for effective joint decision-making between patients and their physicians.

The authors conducted a national survey of the members of the Crohn's and Colitis Foundation of Canada (CCFC) $(12,13)$. The survey included 2828 people with IBD. The survey found that $23.6 \%$ of respondents were currently using CAM specifically for their IBD (13). Herbal- or plant-based therapies were the most commonly reported. Common benefits attributed to the use of CAM were an improved sense of well-being and energy level, reduced IBD symptoms, and an increased sense of control over the disease. This paper reports the findings on: factors associated with use of CAM; reasons commonly cited for use or nonuse of CAM; and correlations between the factors associated with use of CAM and reasons for CAM use. When selecting factors that could be associated with CAM use, the authors were guided by their previous studies $(4,5,14)$, as well as other studies on CAM use by the general public and patients with IBD $(3,6,9-11)$. The factors examined in the present study included: patient demographics; disease and treatment history; health behaviours; and health attitudes.

\section{PATIENTS AND METHODS}

A detailed description of the study methods has been previously published $(12,13)$. The study was approved by the Conjoint Health Research Ethics Board of the University of Calgary.

\section{Study population}

In brief, 4453 members of the CCFC were sent a study package in their stated language preference. A cover letter indicated that the questionnaire was to be completed only by the addressee (the CCFC member). The first questionnaire was mailed in September and October 2001. A second questionnaire was sent to nonrespondents approximately eight weeks later. Questionnaire packages were returned due to wrong addresses for 101 members. Questionnaires were returned by or for 3284 members $(75.5 \%)$. Four hundred fifty-six responses were excluded from the final analysis sample because they did not meet eligibility criteria (younger than 16 years of age, did not have IBD, deceased, resident outside of Canada) or they had only completed parts of the questionnaire. The authors have previously described how the sample for the present study differs from population- and clinicbased IBD samples (12).

\section{Instrument}

The questionnaire for the present study was based on the authors' previous surveys and other published surveys of CAM use. English and French language versions were created. The draft questionnaire was reviewed by several IBD experts. The French and English language versions were pilot tested in IBD clinics in three different Canadian cities.

Respondents were asked to indicate their use of an extensive list of complementary and alternative therapies. These included therapies that could be part of self-treatment (eg, herbs and diets) and therapies provided by complementary practitioners (eg, chiropractic therapy and acupuncture). The authors did not include vitamins, minerals, prayer or exercise as CAM. Respondents were considered to be current CAM users for IBD if they currently used CAM therapy to help with anything related to their IBD at the time of the survey. Respondents were considered to be current CAM users for other purposes if they currently used CAM therapy for their general health or for other medical problems not related to their IBD. The corresponding author, on request, will provide the complete list of therapies included in the questionnaire.

Demographic variables included age, sex, province of residence, highest level of education and annual household income. Because $19.5 \%$ of respondents declined to answer the question on household income, the average household income for their area of residence from the 2001 Canadian Census was used as a proxy by linking their postal code of residence to a census enumeration area (15). Disease and treatment history variables included type and duration of IBD, current disease activity, medication use over the previous 12 months, type of physician they depended on most for their IBD, prior hospitalization and surgery, and disease-related concerns. Because the authors were examining factors that affected patient decision-making, a subjective measure of IBD activity was used. Current IBD disease activity was measured using a single item on self-assessed global disease activity, ("How would you rate the activity of your IBD today?") with a 7-point Likert scale that ranged from 'totally inactive' to 'terrible, worse than it has ever been'. For this analysis, activity was collapsed into four categories (inactive, mild, moderate and severe). Current disease-related concerns were measured using the Rating Form of IBD Concerns (16). Health behaviour variables included the use of exercise and prayer to help specifically with IBD. Health attitude variables included the degree of confidence patients had in the physician they depended on most for their IBD treatment, and the desired role patients wanted for their treatment (ie, whether they preferred to make the final decision, preferred to share responsibility with the doctor or preferred that the doctor made the final decision) (17).

Current or previous users of CAM for their IBD were asked to rate the importance of 11 statements about reasons why they had used CAM for their IBD, on a Likert scale of 1 (not important) through 5 (very important). The authors combined scores 4 and 5 as 'important' and 1 through 3 as 'not important'. Similarly, patients who had never used CAM were asked to rate 10 statements about reasons why they had never used CAM. The reasons for use and nonuse of CAM included items that represented health attitudes towards CAM (eg, "I value the emphasis complementary treatments place on treating the whole person"), items that represented health attitudes or experiences towards conventional medicine (eg, "Conventional IBD treatments I tried did not help my IBD") and items that were largely independent of health attitudes or disease experiences (eg, "I heard or read that complementary treatments might be helpful").

\section{Statistical analysis}

Based on their responses, respondents were classified as having Crohn's disease or ulcerative colitis (including those who classified 
TABLE 1

Demographic characteristics

\begin{tabular}{|c|c|c|}
\hline & $C D(n=1787)$ & UC $(n=1041)$ \\
\hline Age, mean (SD) & $46.3(14.2)$ & $47.9(14.2)$ \\
\hline Female, n (\%) & $1126(63.2)$ & $603(58.0)$ \\
\hline \multicolumn{3}{|l|}{ Education, $\mathrm{n}(\%)$} \\
\hline Below high school & $167(9.4)$ & $101(9.7)$ \\
\hline High school diploma & $318(17.8)$ & $176(16.9)$ \\
\hline Technical college or some university & $663(37.1)$ & $354(34.0)$ \\
\hline University degree & $638(35.7)$ & $409(39.3)$ \\
\hline \multicolumn{3}{|l|}{ Household income, n (\%) } \\
\hline Below $\$ 20,000$ & $105(5.9)$ & $69(6.6)$ \\
\hline$\$ 21,000$ to $\$ 40,000$ & $313(17.5)$ & $163(15.7)$ \\
\hline$\$ 41,000$ to $\$ 60,000$ & $428(24.0)$ & $234(22.5)$ \\
\hline$\$ 61,000$ to $\$ 80,000$ & $369(20.7)$ & $212(20.4)$ \\
\hline Above $\$ 80,000$ & $569(31.9)$ & $362(34.8)$ \\
\hline \multicolumn{3}{|l|}{ Residential region, n (\%) } \\
\hline Maritime provinces & $100(5.6)$ & $55(5.3)$ \\
\hline Quebec & $309(17.3)$ & $155(14.9)$ \\
\hline Ontario & $771(43.2)$ & $534(51.4)$ \\
\hline Manitoba, Saskatchewan, Alberta & $442(24.8)$ & $194(18.7)$ \\
\hline British Columbia and Territories & $164(9.2)$ & $102(9.8)$ \\
\hline
\end{tabular}

CD Crohn's disease; UC Ulcerative colitis

themselves as having indeterminate colitis). To determine significant associations with current CAM use, bivariate analyses were first conducted to detect variables that were associated with the use of CAM, using $\chi^{2}$ tests and independent samples $t$ tests, depending on the level of measurement. The authors used a conservative $P$ value $(P>0.05)$ to exclude variables from further analysis. Retained variables were then examined in multivariate logistical regression analyses. A backward elimination procedure and likelihood ratio tests were used to create the final model. Variables were kept in the model if they were significantly $(\mathrm{P}<0.05)$ associated with the use of CAM. This analysis was conducted separately for patients with Crohn's disease and those with ulcerative colitis. Strength of association was measured by ORs and 95\% CIs.

Exploratory analyses were conducted to determine associations among patient characteristics, concerns, health attitudes and behaviours, and stated reasons for CAM use. This was performed using contingency tables and $\chi^{2}$ tests or logistical regression to calculate P values, ORs and associated 95\% CIs.

\section{Study population}

\section{RESULTS}

The demographic, disease and treatment characteristics, health attitudes and behaviours of the 2828 subjects with Crohn's disease and colitis included in the study are shown in Tables 1 and 2. Patients classified as having ulcerative colitis included 128 who classified themselves as having 'indeterminate colitis or not clear which type'. Overall, 1336 (47\%) subjects used CAM to manage their IBD at some time and 666 (24\%) continued to use CAM. A more detailed description of patterns of CAM use along with a description of the common therapies reported, use of complementary practitioners and perceived effects of CAM can be found elsewhere (13).

Factors associated with use of CAM for IBD

Five variables were excluded from further evaluation because of their insignificant association with current CAM use for
TABLE 2

Disease and treatment characteristics, and health attitudes and behaviours

\begin{tabular}{|c|c|c|}
\hline & $C D(n=1787)$ & UC $(n=1041)$ \\
\hline IBD duration, mean (SD) & $18.4(10.7)$ & $15.1(10.3)$ \\
\hline \multicolumn{3}{|l|}{ Activity of IBD, $\mathrm{n}(\%)$} \\
\hline Inactive & $329(18.7)$ & $262(25.8)$ \\
\hline Mild & $607(34.6)$ & $341(33.5)$ \\
\hline Moderate & $616(35.1)$ & $312(30.7)$ \\
\hline Severe & $204(11.6)$ & $102(10.0)$ \\
\hline $\begin{array}{l}\text { Dependence on gastroenterologist } \\
\text { for IBD, } n(\%)\end{array}$ & $1202(67.3)$ & $698(67.1)$ \\
\hline Concerns about IBD, mean (SD) & $39.8(20.4)$ & $38.7(21.5)$ \\
\hline \multicolumn{3}{|l|}{ Medication or treatment, $\mathrm{n}(\%)$} \\
\hline Oral steroid for IBD & $623(34.9)$ & $305(29.3)$ \\
\hline Azathioprine/6-mercaptopurine & $424(23.7)$ & $126(12.1)$ \\
\hline Intravenous drug use for IBD & $173(9.7)$ & $59(5.7)$ \\
\hline Hospitalization for IBD & $816(45.7)$ & $263(25.3)$ \\
\hline Surgery for IBD & $1159(64.9)$ & $174(16.7)$ \\
\hline \multicolumn{3}{|l|}{ Health attitudes and behaviours, $\mathrm{n}(\%)$} \\
\hline Confident in care physician & $1438(80.5)$ & $825(79.3)$ \\
\hline \multicolumn{3}{|l|}{ Perceived role in treatment, $\mathrm{n}(\%)$} \\
\hline Patient decides with doctor's input & $622(35.5)$ & $364(35.8)$ \\
\hline Shared patient/physician decisions & $806(46.0)$ & $428(42.1)$ \\
\hline Doctor decides with patient's input & $325(18.5)$ & $225(22.1)$ \\
\hline Use of CAM for other purposes, $n(\%)$ & $572(32.0)$ & $355(34.1)$ \\
\hline \multicolumn{3}{|l|}{ Use of exercise to help with IBD, $n(\%)$} \\
\hline Not at all & $574(33.0)$ & $309(31.1)$ \\
\hline A little & $822(47.2)$ & $433(43.6)$ \\
\hline A lot & $345(19.8)$ & $251(25.3)$ \\
\hline \multicolumn{3}{|l|}{ Use of prayer to help with IBD, $n(\%)$} \\
\hline Not at all & 847 (49.5) & $492(50.1)$ \\
\hline A little & $599(35.0)$ & $324(33.0)$ \\
\hline A lot & $264(15.4)$ & $166(16.9)$ \\
\hline
\end{tabular}

CAM Complementary and alternative medicine; $C D$ Crohn's disease; IBD Inflammatory bowel disease; UC UIcerative colitis

IBD in the bivariate analyses $(\mathrm{P}>0.05)$. For Crohn's disease, the excluded variables were education, household income, dependence on a gastroenterologist for IBD treatment, use of azathioprine/6-mercaptopurine in the previous 12 months and degree of confidence in their physician. For ulcerative colitis, the excluded variables were sex, household income, hospitalization in previous five years, use of oral steroids in the previous 12 months and dependence on a gastroenterologist for IBD treatment. The final logistical regression models with the variables significantly associated with current CAM use are presented in Table 3.

Six variables were associated with CAM use in each of the models for Crohn's disease and ulcerative colitis. Despite the fact that models for Crohn's disease and ulcerative colitis were created separately, five of the six variables were the same in both models. The five variables that were significantly associated with current use of CAM for both patients with Crohn's disease and ulcerative colitis were: disease activity; patient's perceived role in IBD treatment; use of CAM for other purposes; use of exercise to help with IBD; and use of prayer to help with IBD.

For the four ordinal variables (disease activity, perceived role in IBD treatment, use of exercise and prayer to help with IBD), a gradient in the strength of the associations (OR) was 
TABLE 3

Significant associations with current complementary and alternative medicine (CAM) use for Crohn's disease (CD) and ulcerative colitis (UC)

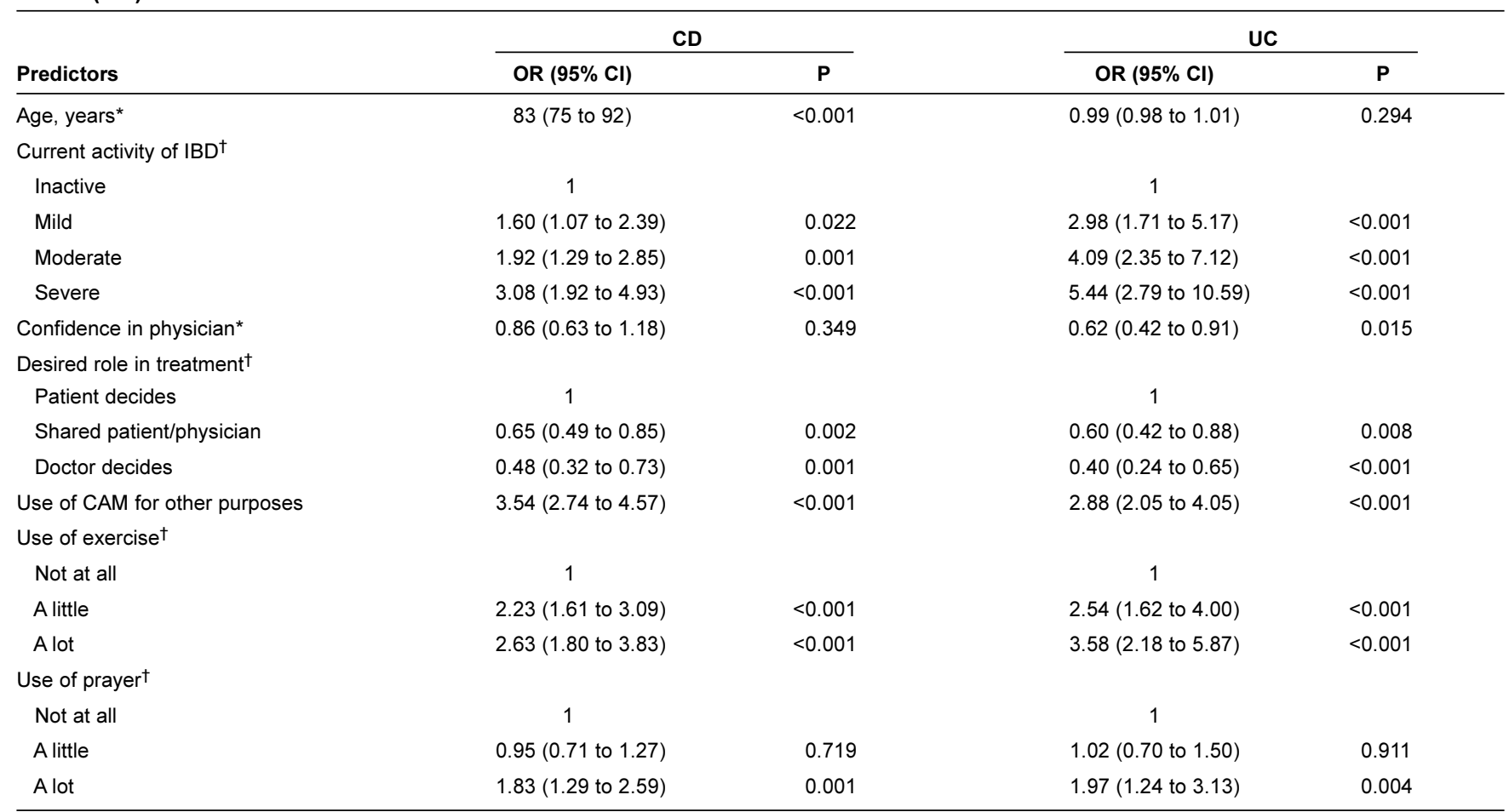

*'Confidence in care physician' for CD and 'age' for UC were not significant predictors, but were added into the models for comparison between CD and UC. The addition of the two variables into the final model did not change either the logistical parameters (OR and $95 \%$ CI) or their significance; ${ }^{+}$For categorical variables with more than one level, the OR is in comparison to the baseline level. For example, the OR for mild disease activity represents the ratio of the odds of patients with mild disease using CAM compared with the odds of those with inactive disease using CAM. IBD Inflammatory bowel disease

TABLE 4

Ratings of respondents' reasons for use of complementary and alternative medicine (CAM) for their inflammatory bowel disease (IBD), sorted by proportion

\begin{tabular}{lc}
\hline Respondents' reasons for using CAM & $\begin{array}{c}\text { Proportion } \\
\text { (\%) }\end{array}$ \\
\hline I wanted greater control over my life and my IBD & 72.9 \\
I heard or read that complementary treatments might be & 61.0 \\
helpful & 48.6 \\
I value the emphasis complementary treatments place on & \\
treating the whole person & 42.1 \\
Conventional IBD treatments I tried did not help my IBD & 37.1 \\
Conventional IBD treatments helped my IBD, but I believed & 36.2 \\
$\quad$ complementary therapies would be more effective & 35.3 \\
I suffered side effects from the conventional IBD treatments \\
I was worried that I would suffer side effects from \\
$\begin{array}{l}\text { conventional IBD treatments } \\
\text { My doctor(s) did not give me the care or 'human touch' that } \\
\text { I needed }\end{array}$ \\
$\begin{array}{l}\text { My doctors(s) spoke of my disease in terms that left me } \\
\text { little, if any, hope }\end{array}$ \\
$\begin{array}{l}\text { I think differently about the causes of treatment IBD than my } \\
\text { doctor(s) and thus prefer different treatments than my }\end{array}$ \\
$\begin{array}{l}\text { My doctor(s) do } \\
\text { lifestyle habits }\end{array}$ \\
\hline
\end{tabular}

apparent across the categories. For example, the OR for disease activity progressively increased with greater level of disease activity.

\section{TABLE 5}

Ratings of respondents' reasons for not using complementary and alternative medicine (CAM) for their inflammatory bowel disease (IBD), sorted by proportion

\begin{tabular}{lc}
\hline Respondents' responses for not using CAM & $\begin{array}{c}\text { Proportion } \\
\text { (\%) }\end{array}$ \\
\hline The conventional treatments seemed to be successful and & 62.4 \\
therefore I did not need to try other forms of therapy & 54.8 \\
I felt that not enough was known & 47.4 \\
I did not believe that it would work & 46.7 \\
I worried that it might interfere with my conventional medical & \\
treatments & 43.4 \\
I felt that it was not 'scientific' & 42.6 \\
I was unaware of any complementary therapies for my IBD & 41.8 \\
My IBD doctor did not approve or recommend it & 40.5 \\
I worried that I might suffer side effects from the complementary & \\
therapy & 22.6 \\
Complementary therapy cost too much & 7.1 \\
\hline
\end{tabular}

Reasons for use and nonuse of CAM

In this analysis, the authors did not distinguish between Crohn's disease and ulcerative colitis patients' reasons for using or not using CAM because of a lack of a strong a priori theoretical reason to do so, and the similar predictors found for CAM use for each group. Reasons cited by patients for using CAM for their IBD are shown in Table 4. Reasons cited by patients for never using CAM for their IBD are shown in Table 5. 
TABLE 6

Associations between characteristics of complementary and alternative medicine (CAM) users and stated reasons for using CAM

\begin{tabular}{|c|c|c|c|c|c|}
\hline & $\begin{array}{c}\text { Wanted greater } \\
\text { control } \\
\text { OR }(95 \% \mathrm{Cl})\end{array}$ & $\begin{array}{l}\text { Heard or read that } \\
\text { CAM might help } \\
\text { OR }(95 \% \mathrm{Cl})\end{array}$ & $\begin{array}{l}\text { Emphasis on } \\
\text { whole person } \\
\text { OR }(95 \% \mathrm{CI})\end{array}$ & $\begin{array}{l}\text { Conventional } \\
\text { treatments no help } \\
\text { OR }(95 \% \mathrm{Cl})\end{array}$ & $\begin{array}{c}\text { Thinks differently about } \\
\text { causes and treatment } \\
\text { OR }(95 \% \mathrm{Cl})\end{array}$ \\
\hline $\operatorname{Sex}^{*}$ & $1.75(1.26$ to 2.46$)$ & $1.15(0.85$ to 1.55$)$ & $1.90(1.41$ to 2.57$)$ & $1.29(0.95$ to 1.76$)$ & $0.95(0.66$ to 1.37$)$ \\
\hline $\mathrm{Age}^{\dagger}$ & $0.97(0.84$ to 1.11$)$ & $0.84(0.75$ to 0.95$)$ & $1.03(0.91$ to 1.16$)$ & $0.84(0.74$ to 0.95$)$ & $0.97(0.83$ to 1.12$)$ \\
\hline Education $\ddagger$ & $0.67(0.29$ to 1.58$)$ & $1.16(0.60$ to 2.27$)$ & 1.35 (0.69 to 2.64$)$ & $1.50(0.74$ to 3.02$)$ & $0.65(0.31$ to 1.37$)$ \\
\hline Exercise $^{\ddagger}$ & $2.38(1.45$ to 3.90$)$ & 1.78 (1.17 to 2.71$)$ & $3.10(2.02$ to 4.74$)$ & $1.00(0.66$ to 1.52$)$ & $1.63(0.96$ to 2.79$)$ \\
\hline Prayer $\ddagger$ & 1.80 (1.13 to 2.88$)$ & $1.84(1.23$ to 2.76$)$ & $2.38(1.61$ to 3.51$)$ & $1.56(1.07$ to 2.27$)$ & $2.00(1.29$ to 3.10$)$ \\
\hline Role $^{\ddagger}$ & $0.66(0.39$ to 1.12$)$ & $0.74(0.46$ to 1.19$)$ & 0.29 (0.18 to 0.49$)$ & $0.66(0.39$ to 1.10$)$ & $0.36(0.20$ to 0.73$)$ \\
\hline Disease activity ${ }^{\ddagger}$ & $0.92(0.49$ to 1.70$)$ & $1.10(0.66$ to 1.84$)$ & $0.61(0.37$ to 1.03$)$ & 2.04 (1.22 to 3.40$)$ & 1.01 (0.54 to 1.89$)$ \\
\hline
\end{tabular}

${ }^{*}$ Females versus males; ${ }^{\dagger}$ Age in 10-year increments; ${ }^{\ddagger}$ For ordered variables: highest category versus lowest (eg, education: university degree versus less than high school; role: doctor decides versus patient decides). OR $>1.0$ indicates that those with the characteristics were more likely to report the reason for CAM use than those without the characteristics. For example, women were 1.75 times more likely than men to state that wanting greater control was a reason for their CAM use. $O R<1.0$ indicates that a group was less likely to report that reason. Statistically significant associations are shown in bold type

Bivariate associations between the factors that were examined as potential associations with CAM use (patient demographics, disease and treatment characteristics, and health attitudes and behaviours) and reasons for using CAM were explored. Table 6 shows the associations between selected factors and five of the reasons for CAM use. For simplicity, only the highest and lowest level of each categorical variable is included. "I wanted greater control over my life and my IBD" was the most common reason given for using CAM. Women, patients who used exercise to treat their IBD and those who used prayer to treat their IBD were more likely to report that a desire for greater control was an important reason for their use of CAM.

The use of prayer was positively associated with more of the reasons for CAM use (10 of the 11 reasons) than any of the other variables. The only reason it was not significantly associated with was "I believed complementary therapies would be more effective". As can be seen from Table 6, use of prayer is associated with reasons that reflect both disease experiences (lack of benefit from conventional treatment) and health attitudes (value emphasis on the whole person; patients thinking differently about causes and treatment than their doctors). In contrast, education was not associated with any of the reasons for using CAM for IBD.

CAM's emphasis on treating the whole person, the third most common reason for starting CAM, was ranked as an important reason for CAM use by women and those who used prayer and exercise to treat their IBD. In contrast, those who relied on their doctor to make treatment decisions were less likely to report this reason than those who preferred to make their own treatment decisions.

\section{DISCUSSION}

It is well-recognized that CAM use is common among people with IBD, as it is among the general public $(3,4,6,9,10,13)$. In this study (13), we found that $47 \%$ of patients had used or were currently using CAM for their IBD and an additional 9\% were using CAM for other reasons. In the present study, we investigated factors associated with the use of CAM for IBD and reasons for use and nonuse of CAM using a large community-based and geographically diverse sample.

Demographic characteristics have been frequently associated with the use of CAM. For example, Eisenberg et al (9) found in a survey of the American general population that CAM use was more common among women, younger age groups, those with a college education and those with incomes above $\$ 50,000 /$ year. In our earlier survey (4), we found no association between sex, age or education level and CAM use. In a multicountry study, Rawsthorne et al (3) found an association with income, but not for other demographic variables. Langmead et al (18) found no association between demographic variables in a study of 101 British IBD patients. However, these studies, as with all studies examining CAM use by patients with IBD, had relatively small sample sizes (fewer than 300 subjects), which contrasts with the large sample sizes found in most general population surveys. Therefore, inadequate power could be responsible for the failure to find these associations in previous IBD studies. However, in our survey of over 2800 IBD patients, apart from age in Crohn's disease patients, other demographic variables were not associated with the use of CAM for IBD. Therefore, in contrast to the general population, demographic factors are not clearly associated with IBD patients' use of CAM.

Why are these demographic characteristics not associated with CAM use in IBD patients? It may be that as the use of CAM grows and becomes mainstream, these traditional boundaries are being erased. CAM use is no longer limited to the young and well-educated, because individuals from all layers of society increasingly use CAM. For example, Astin (10) suggested that an association with education may reflect that those with higher education are: more likely to be exposed to various alternative forms of health care through their own reading; more likely to educate themselves about their disease and available treatments; and more likely to question the authority of conventional practitioners. However, the growth of CAM has resulted in greater public exposure to these therapies. Information about CAM, of varying quality, is readily available to patients through local health food stores, complementary practitioners, on television and over the Internet. It is now unlikely that those with higher education are any more likely to be exposed to CAM.

Of the disease and treatment characteristics examined, only current disease activity was associated with CAM use. This association was seen for both Crohn's disease and ulcerative colitis and a dose response was observed, with higher levels of disease activity being associated with greater likelihood of CAM use. An association between disease activity and CAM use is supported by the reasons cited by patients for using or not 
using CAM. Success and lack of success with conventional therapies were important reasons cited by CAM nonusers and users, respectively. Treatment characteristics were focused on previous events (ever having surgery, prior hospitalization, medical treatment in the previous 12 months) and would therefore be expected to potentially have less influence on contemporaneous patient decision-making, such as the decision to continue using CAM, than current disease activity.

In contrast to demographic and disease characteristics, health attitudes and behaviours were clearly associated with the use of CAM by Canadian IBD patients. The results suggest that CAM users desire a more active role in managing their disease. A desire for greater control over "my life and my IBD" was the most common reason given for starting CAM. Use of CAM was much more common in patients who wanted to play a greater role in treatment decisions than those who wished to leave decisions up to their physicians. Given the complexity of medical and surgical treatments of IBD, patients may find that they can best play an active role through their lifestyle and the use of CAM.

Prayer and exercise were consistently associated with use of CAM and with many of the reasons for using CAM, especially for a desire for greater control and an emphasis on the whole person. Therefore, those who use CAM, exercise and prayer must believe that they have the power to affect the course of their disease. They must see themselves not only as a decisionmaker but also as a healer. In general, conventional Western medicine emphasizes external solutions to medical problems, such as prescription medicines and surgery. Many alternative medical systems emphasize the patient's role in healing (19). This does not mean that these patients abandon conventional medicine. Indeed, we previously reported (13) that CAM users and non-CAM users with any given level of disease activity were just as likely to be using conventional medicines. Instead, CAM users appear to seek multiple means to control their disease, including those provided by conventional health care providers, those provided by complementary practitioners and those that they can carry out themselves. Our findings are consistent with general population surveys where CAM use has been associated with patients' attitudes towards the nature and meaning of health and illness, and with their spiritual and religious belief (11). As Astin (10) suggested, "individuals are attracted to the nonconventional therapies because they find in them an acknowledgement of the importance of treating illness within a larger context of spirituality and life meaning".

In patients with IBD, a disease that affects all age groups and affects men and women relatively equally, it should not be surprising that CAM use is less influenced by simple demographic characteristics than by disease experiences and by the patients' health attitudes and behaviours. Eisenberg et al (11) indicated that the main reasons for the general public to use alternative

\section{REFERENCES}

1. Smart HL, Mayberry JF, Atkinson M. Alternative medicine consultations and remedies in patients with the irritable bowel syndrome. Gut 1986;27:826-8.

2. Verhoef MJ, Sutherland LR, Brkich L. Use of alternative medicine by patients attending a gastroenterology clinic. CMAJ 1990;142:121-5.

3. Rawsthorne P, Shanahan F, Cronin NC, et al. An international survey of the use and attitudes regarding alternative medicine by patients with inflammatory bowel disease. Am J Gastroenterol 1999;94:1298-303.

4. Hilsden RJ, Scott CM, Verhoef MJ. Complementary medicine use by patients with inflammatory bowel disease. Am J Gastroenterol 1998;93:697-701. therapies were that conventional medicine had been exhausted, had an indeterminate effectiveness, or came with side effects or significant associated risks. This appears to hold true in IBD patients. Lack of response or dissatisfaction with conventional IBD treatments would be a strong incentive for patients to seek alternative forms of treatment. Indeed, non-CAM users most commonly cited the success of conventional medicines as an important reason why they had not sought CAM therapies. The cost of CAM did not seem to be an important factor in preventing CAM use (presumably mediated by income) because few nonusers identified the cost of CAM as an important deterrent of their use.

Because we used a self-completed mailed questionnaire, our study is limited by the accuracy of the information provided by the respondents, including type of disease and CAM use. Our study is also not a true population-based study and there are likely important differences in our population compared with the IBD population at large (12). However, ours is the largest survey to date, and we used a comprehensive, carefully developed and tested questionnaire that provided rich and detailed information on CAM use. Future studies attempting to understand IBD patients' use of CAM should focus more carefully on individuals' health attitudes and behaviours to better understand how these factors lead to CAM use and what implications these factors could have on conventional medical care.

Practicing physicians must understand that, for many patients with IBD, CAM use is intimately connected to how they view health and their role in health care, both as decisionmaker and self-healer. Counselling patients regarding CAM use, and by extension all aspects of medical care, must take into consideration not only the patients' disease but also their unique set of health attitudes. Furthermore, these results suggest that there is a large proportion of IBD patients who wish to play a greater role in the management of their disease. Physicians and the health care system in general need to explore ways to enhance shared decision-making and responsibility.

In conclusion, we found that CAM use by patients with IBD is most closely associated with disease activity and health attitudes and behaviours, including their desired role in treatment decisions and their use of prayer and exercise. Consistent with these findings, the most commonly reported reason for using CAM was a desire for greater control over one's life and IBD.

ACKNOWLEDGEMENTS: The authors would like to thank Michael Howorth, Executive Director, and the staff of the Crohn's and Colitis Foundation for their assistance with this study. This project was supported by an Operating Grant from the Crohn's and Colitis Foundation of Canada. Dr Hilsden is an Alberta Heritage Foundation for Medical Research Population Health Investigator.

5. Hilsden RJ, Meddings JB, Verhoef MJ. Complementary and alternative medicine use by patients with inflammatory bowel disease: An internet survey. Can J Gastroenterol 1999; 13:327-32.

6. Moser G, Tillinger W, Sachs G, et al. Relationship between the use of unconventional therapies and disease-related concerns: A study of patients with inflammatory bowel disease. J Psychosom Res 1996;40:503-9.

7. Quattropani C, Ausfeld B, Straumann A, Heer P, Seibold F. Complementary alternative medicine in patients with inflammatory bowel disease: Use and attitudes. Scand J Gastroenterol 2003;38:277-82.

8. Heuschkel R, Afzal N, Wuerth A, et al. Complementary medicine 
use in children and young adults with inflammatory bowel disease. Am J Gastroenterology 2002;97:382-8.

9. Eisenberg DM, Davis RB, Ettner SL, et al. Trends in alternative medicine use in the United States, 1990-1997. Results of a follow-up national survey. JAMA 1998;280:1569-75.

10. Astin JA. Why patients use alternative medicine: Results of a national study. JAMA 1998;279:1548-53.

11. Eisenberg DM, Kessler RC, Foster C, Norlock FE, Calkins DR, Delbanco TL. Unconventional medicine in the United States. Prevalence, costs, and patterns of use. N Engl J Med 1993;328:246-52.

12. Hilsden RJ, Verhoef MJ, Best A, Pocobelli G. A national survey on the patterns of treatment of inflammatory bowel disease in Canada. BMC Gastroenterology 2003;3:10.

13. Hilsden RJ, Verhoef MJ, Best A, Pocobelli G. Complementary and alternative medicine use by Canadian patients with inflammatory bowel disease: Results from a national survey. Am J Gastroenterol 2003;98:1563-8.
14. Scott CM, Verhoef MJ, Hilsden RJ. Inflammatory bowel disease patients' decisions to use complementary therapies: Links to existing models of care. Complement Ther Med 2003;11:22-7.

15. Statistics Canada. The Postal Code Conversion File (PCCF) Users Guide, January 1996 Version. Ottawa: Geography Division, Statistics Canada, 1996.

16. Drossman DA, Leserman J, Li ZM, Mitchell CM, Zagami EA, Patrick DL. The rating form of IBD patient concerns: A new measure of health status. Psychosom Med 1991;53:701-12.

17. Degner LF, Sloan JA, Venkatesh P. The Control Preferences Scale. Can J Nurs Res 1997;29:21-43.

18. Langmead L, Chitnis M, Rampton DS. Use of complementary therapies by patients with IBD may indicate psychosocial distress. Inflamm Bowel Dis 2002;8:174-9.

19. Aakster CW. Concepts in alternative medicine. Soc Sci Med 1986;22:265-73. 


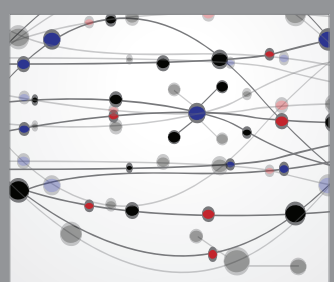

The Scientific World Journal
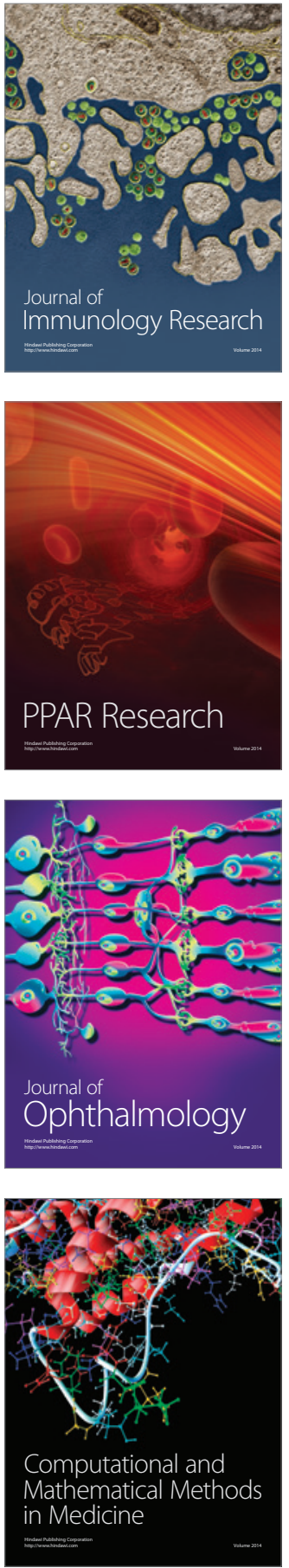

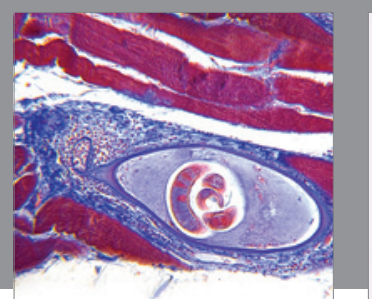

Gastroenterology Research and Practice

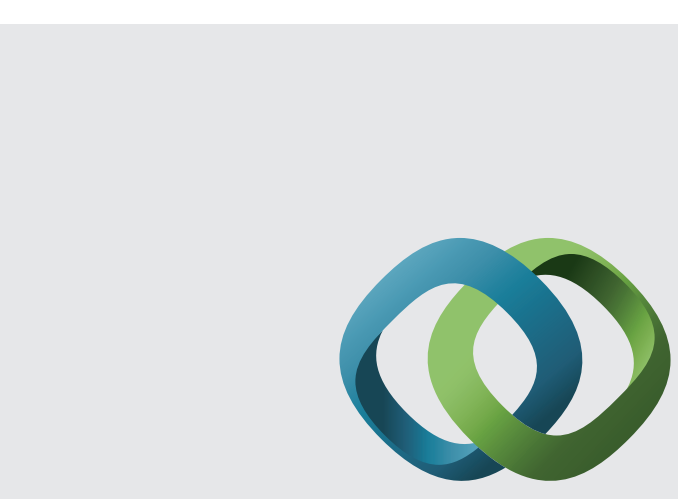

\section{Hindawi}

Submit your manuscripts at

http://www.hindawi.com
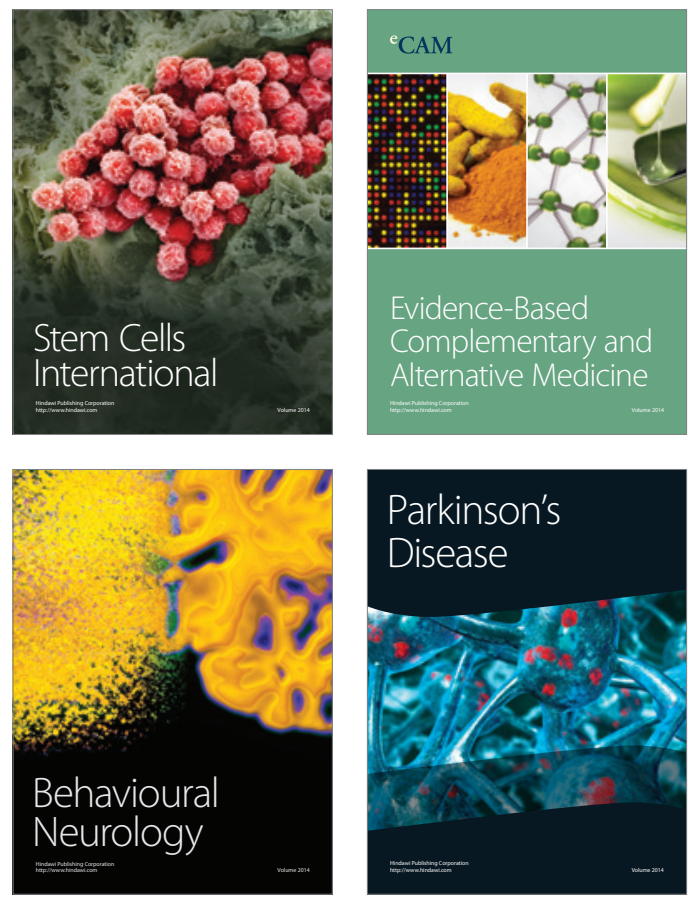
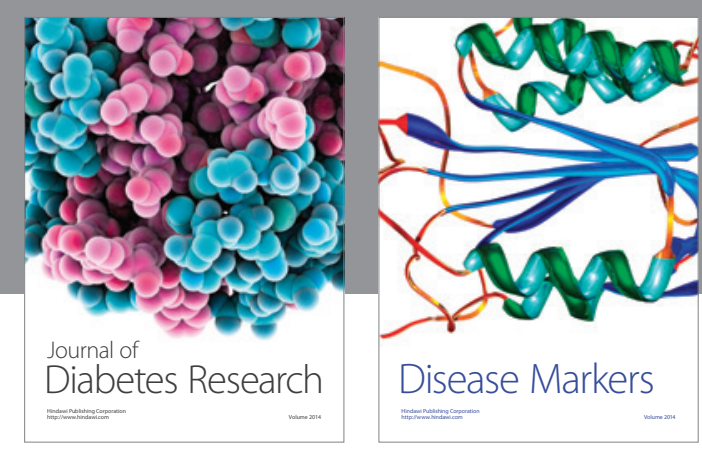

Disease Markers
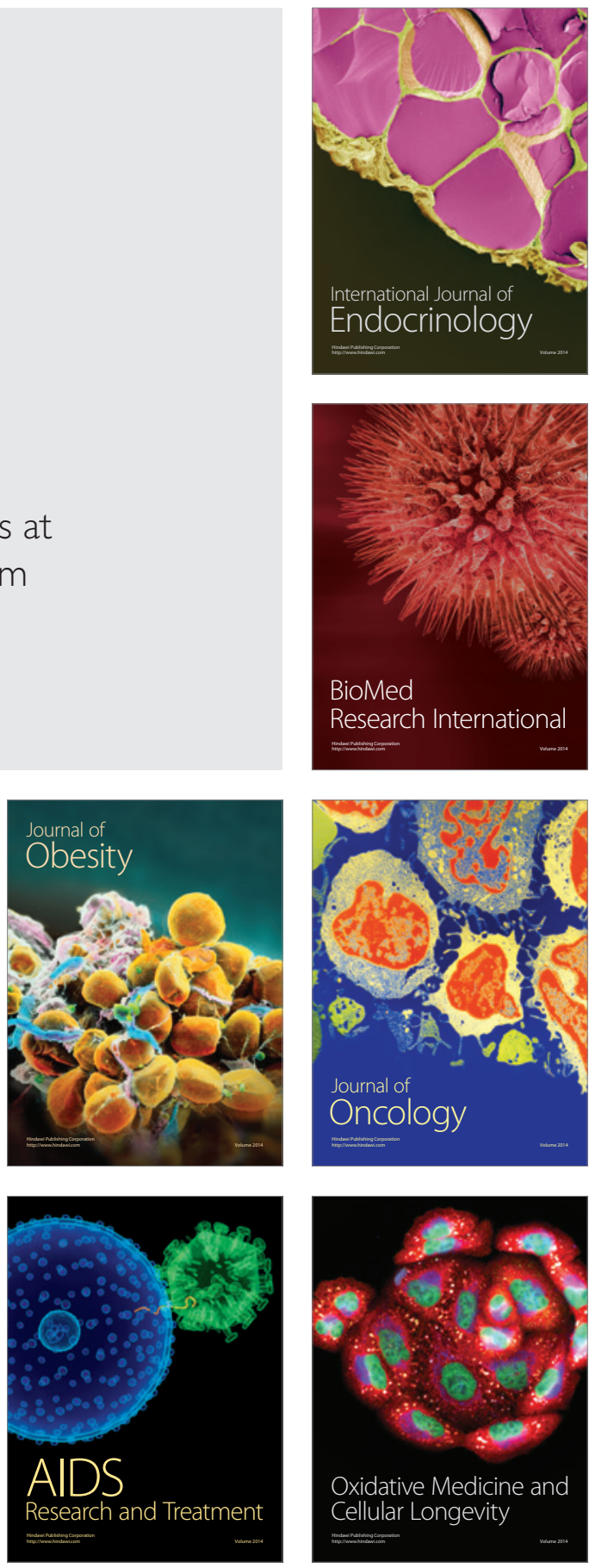